\title{
Using forensic geochemistry via fish otoliths to investigate an illegal fish introduction
}

\begin{tabular}{|r|l|}
\hline Journal: & Canadian Journal of Fisheries and Aquatic Sciences \\
\hline Manuscript ID & Cjfas-2018-0082.R1 \\
\hline Manuscript Type: & Rapid Communication \\
\hline Date Submitted by the & $16-J u l-2018$ \\
\hline $\begin{array}{r}\text { Complete List of Authors: } \\
\text { Keyword: }\end{array}$ & $\begin{array}{l}\text { Bourret, Samuel; Montana Fish Wildlife and Parks, Fisheries } \\
\text { Clancy, Niall; Utah State Universiy, Watershed Sciences } \\
\text { General, TRACE ELEMENTS < General }\end{array}$ \\
\hline $\begin{array}{r}\text { Is the invited manuscript for } \\
\text { consideration in a Special } \\
\text { Issue? : }\end{array}$ & Not applicable (regular submission) \\
\hline
\end{tabular}

\section{SCHOLARONE Manuscripts}




\section{Using Forensic Geochemistry via Fish Otoliths to Investigate an Illegal Fish Introduction}

2 Samuel L. Bourret ${ }^{1^{*}}$ Email: sbourret@mt.gov

3 Niall G. Clancy ${ }^{2} \quad$ Email: niall.clancy@aggiemail.usu.edu

4

$5 \quad{ }^{1}$ Montana Fish, Wildlife \& Parks, 190 N. Meridian Rd, Kalispell, MT 59901, USA

$6 \quad{ }^{2}$ Department of Watershed Sciences, Utah State University, Logan, Utah 84322, USA

7

$8 \quad{ }^{*}$ Corresponding Author:

9 S.L. Bourret

10 Montana Fish, Wildlife \& Parks, 190 N. Meridian Rd, Kalispell, MT 59901, USA

11 Phone: (406) 751-4556

12 Fax: (406) 257-0349

13

14

15

16

For submission to CJFAS, Rapid Communication

17

18 
Illegal fish introductions create some of the most challenging problems for resource managers

21 because of their potential to harm existing recreational fisheries and their impact on species of

22 conservation concern. Determining the origin of a suspected illegal fish introduction can aid managers

23 in preventing the colonization and subsequent ecosystem impacts of introduced species. In this study,

24 we used forensic geochemistry via fish otoliths to investigate an illegal Walleye introduction in Swan

25 Lake, Montana, which provides critical habitat for threatened Bull Trout and native Westslope Cutthroat

26 Trout. Core to edge geochemical profiles of ${ }^{87} \mathrm{Sr} /{ }^{86} \mathrm{Sr}$ and $\mathrm{Sr} / \mathrm{Ca}$ ratios in the Walleye otoliths revealed

27 that these fish had been introduced to Swan Lake within the past growing season and their geochemical

28 signature matched that of Walleye sampled from Lake Helena, Montana located 309 road kilometers

29 away. This research highlights application of a tool fisheries managers can use to identify the natal

30 waterbody source of illegally introduced fish.

31

32 Keywords: Invasive Species, Otoliths, Isotopes, Trace Elements

33

34

35

36

37 


\section{INTRODUCTION}

Biotic invasions have greatly altered both aquatic and terrestrial systems worldwide (Mack et al.

2000; Simberloff et al. 2013). In freshwaters, the introduction and spread of non-native fishes has decreased biodiversity and imperiled freshwater species (Jenkins 2003), consequently impacting local economies and cultural resources. The introduction of non-native fishes has a long history in North

44 America. Federal and state agencies, including the U.S. Fish Commission (est. 1871), were founded with 45 the mission to increase fishery resources through hatchery propagation and stocking (Nielsen 1999; Rahel 2004). Despite evidence that introducing non-native fishes can have detrimental ecosystem

47 effects, only recently have agencies worked to assess stocking practices and manage invasive species

48 (Johnson et al. 2009). Contemporary methods by which unauthorized fish introductions occur include illegal plants by anglers, bait bucket releases, escapes from aquaculture or aquaria, and ballast water exchange (Benson 1999; Rahel 2004). While some recent fish introductions have been supported by

51 national or local governments (e.g. Azevedo-Santos et al. 2016), illegal planting by anglers is now the most common means by which new species are introduced to waters where they were not historically

53 present. Illegal fish introductions may be perpetuated by the fishery profession's historic practice of

54 stocking, leading to confusion among the public about native fish stocking efforts (Johnson et al. 2009).

55 Such trends are even more troubling given the rise of invasive species denialism (Russell and Blackburn 56 2017). opportunity, creating problems for fisheries managers that may necessitate chemical rehabilitation, 59 suppression programs, or additional fish stocking to supplement the impacted fishery (Johnson et al. 60 2009). However, determining when and where introduced fish will become established is difficult

61 (Garcia-Berthou 2007), and interactions between fish invaders and anthropogenic disturbance make it 
62 difficult to predict the effects invasion may have on ecosystems, recreational fisheries, and native

63 species (Rahel and Olden 2008; Leprieur et al. 2009). Once established, the reduction or elimination of

64 unauthorized fish species is often challenging and resource intensive. With the exception of small

65 isolated waters or in instances where illegal introductions are quickly detected, eradication of species is

66 expensive and challenging (Marr et al. 2010). Therefore, management actions during the initial

67 introduction and dispersal stages provide the greatest chance of preventing the establishment and negative impacts of introduced species (Vander Zanden and Olden 2008). To deter illegal introductions, fisheries managers can use innovative tools and technologies to reliably identify sources of illegal introductions, thus aiding law enforcement in convicting perpetrators, and allowing managers to focus prevention efforts on the waterbodies most at risk. history deposited in the inert concentric layers of $\mathrm{CaCO}_{3}$ in otoliths (Kennedy et al. 2000; BarnettJohnson et al. 2008). Naturally occurring strontium (Sr) substitutes for calcium (Ca) in otoliths and its relative concentration provides a temporal and spatial record of changes in Sr concentration encountered over a fish's lifetime (Campana and Thorrold 2001; Wells et al. 2003). Sr can be found in

77 differing concentrations among waterbodies due to landscape scale variation in geology, land use, and 78 weathering patterns. The influence of hydro-climatic variation on spatial and temporal stability of water chemistry is moderated by drainage size, with relatively large drainages exhibiting stable ${ }^{87} \mathrm{Sr} /{ }^{86} \mathrm{Sr}$ isotope values (Wolf et al. 2012). Dissolved Sr concentrations in water are correlated with otolith Sr/Ca

81 (Wells et al. 2003; Bourret et al. 2014) and ${ }^{87} \mathrm{Sr} /{ }^{86} \mathrm{Sr}$ isotope (Kennedy et al. 1997; Muhlfeld et al. 2005;

82 Brennan et al. 2015) values. The elemental tracer Sr/Ca fluctuates annually and seasonally in the 83 environment and its uptake in fish otoliths is fractionated by temperature, salinity, and physiology. The $84{ }^{87} \mathrm{Sr} /{ }^{86} \mathrm{Sr}$ geochemical signature is temporally stable and has a direct correlation with ambient water 85 concentrations (Muhlfeld et al. 2012; Brennan et al. 2015). Both $\mathrm{Sr} / \mathrm{Ca}$ and ${ }^{87} \mathrm{Sr} /{ }^{86} \mathrm{Sr}$ geochemical 
signatures have proven useful as forensic tools to identify the source and timing of illegal and invasive

87 fish introductions (Munro et al. 2005; Wolff et al. 2012).

The overall goal of this study was to use forensic geochemistry techniques via fish otoliths to determine the natal origin of illegally introduced Walleye (Sander vitreus) in a Montana lake. Our major objectives were to 1) compare the Swan Lake caught Walleye otoliths to Swan Lake origin Lake Trout

91 (Salvelinus namaycush) otoliths to confirm they were illegally introduced, and 2) to build a geochemical

92 database, from the most likely source populations of Walleye, that allowed us to assign the two Walleye 93 to their natal water body.

\section{METHODS}

95 105 Lake.
Study site

Our study area encompassed lakes and reservoirs throughout Montana, USA. A specific focus on Swan Lake, a deep (max depth 70.4 meters), oligotrophic, 1,323 hectare natural lake in the Flathead River drainage of northwest Montana, was the result of illegal fish introductions (Figure 1). Once a pristine environment for native fish species, Swan Lake contains critical habitat for species of conservation concern such as Bull Trout and Westslope Cutthroat Trout, but has been the unfortunate recipient of illegal fish introductions including Northern Pike (Esox Lucius; discovered 1979), Lake Trout (Salvelinus namaycush; discovered 1998), and Walleye (Sander vitreus; discovered 2015), all of which pose significant predation threats to native fish species. Swan Lake is isolated above Big Fork Dam and there are no connected sources of Walleye, making it impossible for Walleye to naturally colonize Swan

Fish Collection 
Two Walleye and three Lake Trout were caught in Swan Lake in October 2015 with large-mesh

108 gill nets $(11.5-12.5 \mathrm{~cm})$ set overnight in shallow Lake Trout spawning habitats. In 2017, Montana Fish,

109 Wildlife \& Parks (MFWP) personnel used experimental mesh gillnets to collect three Walleye for otolith

110 geochemical analysis from each of the 13 lakes and reservoirs in Montana (Figure 1) with the highest

111 number of angler days. Angler days is an estimation of the number of hours spent by anglers fishing for

112 Walleye. The 13 lakes were also nearest in road miles to Swan Lake (Table 1). These waterbodies were

113 sampled to build a geochemical database used to assess the potential sources of the illegally introduced

114 Walleye. Rufus Woods Lake, Washington is another popular nearby Walleye fishery and three Walleye

115 were collected for analysis via hook and line in 2017. These waterbodies were chosen because they

116 represent the fisheries with the highest Walleye fishing pressure in the region.

117 Otolith Geochemistry

Sagittal otoliths were extracted from collected fish with nonmetallic forceps and stored in dry paper scale envelopes. Otoliths were cleaned with Milli-Q water for 5 minutes and dried overnight and embedded in heat activated Crystal Bond epoxy sulcus side up on pre-cleaned 25 x $75 \mathrm{~mm}$ clear glass microscopy slides. Otoliths were polished with 600,800 , and 1200 wet grit silicon carbide adhesive discs

122 in a dorsal plane until the primordium and annual growth rings were visible with reflected light and a

123 compound light microscope.

Otolith sections were assayed for ${ }^{87} \mathrm{Sr} /{ }^{86} \mathrm{Sr}$ and $\mathrm{Sr} / \mathrm{Ca}$ with a laser ablation inductively coupled

125 plasma mass spectrometry (ICP-MS). Analysis included a Thermo Finnigan Neptune multiple collector

126 (MC-ICP-MS) coupled to a New Wave 193-nm laser ablation system at the Woods Hole Oceanographic

127 Institution Plasma Mass Spectrometry Laboratory, following the methods reported by Bourret et al.

128 (2014). ${ }^{87} \mathrm{Sr} /{ }^{86} \mathrm{Sr}$ and $\mathrm{Sr} / \mathrm{Ca}$ ratios were quantified with a single ablated transect from otolith core to 129 edge at a perpendicular angle to growth rings. Laser ablation transects were implemented using a 50 
micron diameter spot size at $100 \%$ output energy, with a pulse rate of $10 \mathrm{~Hz}$, and a scan rate of 5 microns /sec. Analytical accuracy of LA data was evaluated by measuring the ${ }^{87} \mathrm{Sr} /{ }^{86} \mathrm{Sr}$ ratio of the USGS MACS3 carbonate standard during each LA run. The ${ }^{87} \mathrm{Sr} /{ }^{86} \mathrm{Sr}$ LA runs of the carbonate standard mean were $0.70762(N=6,2 S D \pm 0.000135)$, which is within the accepted error value of 0.70754 (Weber et al. 2017). Sr/Ca was measured in otolith samples by converting $88 \mathrm{Sr} / 48 \mathrm{Ca}$ to $\mathrm{Sr} / \mathrm{Ca} \mathrm{mmol} / \mathrm{mol}$, and analytical accuracy (0.3\%) was assessed with repeated analysis of MACS3 solid carbonate standard (USGS).

Core and edge values were gathered from each individual otolith transect by calculating the mean (M) and standard deviation (SD) of ${ }^{87} \mathrm{Sr} /{ }^{86} \mathrm{Sr}$ and $\mathrm{Sr} / \mathrm{Ca}$ from $200 \mu \mathrm{m}$ long sections at each location.

140 We first compared the core to edge transects of the two Swan Lake Walleye with the Lake Trout. We assumed the Lake Trout were born in Swan Lake and inhabited the lake for their entire life history,

142 therefore would have a geochemical transect that we could use as a control to compare to the Walleye.

143 We hypothesized that the two Walleye would have a similar core to edge geochemical transect as the 144 Lake Trout if they were also naturalized in Swan Lake. We directly compared the Swan Lake Walleye ${ }^{87} \mathrm{Sr} /{ }^{86} \mathrm{Sr}$ and $\mathrm{Sr} / \mathrm{Ca}$ core values to the edge values. We also calculated the percent change of Walleye 146 core values and edge values. Next, we compared the ${ }^{87} \mathrm{Sr} /{ }^{86} \mathrm{Sr}$ and $\mathrm{Sr} / \mathrm{Ca}$ core values of the 3 Lake Trout 147 with the core values of the 2 Swan Lake Walleye. To determine when the Walleye were introduced to 148 Swan Lake, we compared the location of the geochemical signatures abrupt change on the otolith axis with the last annuli that corresponds to the fishes' last winter.

151 analysis (DFA) (e.g. Wells et al. 2003; Bourret et al. 2014). ${ }^{87} \mathrm{Sr} /{ }^{86} \mathrm{Sr}$ and Sr/Ca values from the three 152 Walleye otoliths from each suspected source (Figure 1 ) were pooled to form the groups in the DFA 
153

154

155

156

157

158

159

160

161

162

163

164

165

166

167

168

169

170

171

172

173

174

model. The groups were used as the training set in the DFA model with equal prior probability, and jackknifed leave-one-out predictions were used to assess the accuracy of the DFA model predictions. Statistical analyses were conducted in R version 3.2.3 (R development Core Team 2015).

\section{RESULTS}

The otolith core to edge transects from the two Walleye captured in Swan Lake (total lengths = $43.2 \mathrm{~cm}$ and $44.5 \mathrm{~cm}$ ) clearly indicated they were not born in Swan Lake, given the abrupt changes in both ${ }^{87} \mathrm{Sr} /{ }^{86} \mathrm{Sr}$ and $\mathrm{Sr} / \mathrm{Ca}$ starting at $330 \mu \mathrm{m}$ from the otolith core (Figure 2). We found a $2.2 \%$ mean change in ${ }^{87} \mathrm{Sr} /{ }^{86} \mathrm{Sr}$ and $49.44 \%$ change in $\mathrm{Sr} / \mathrm{Ca}$ between core to edge geochemical signatures (Figure 2) Lake Trout from Swan Lake showed very little change in the core to edge geochemical transects, validating their use as a Swan Lake control group. The abrupt change in geochemical signatures of both Walleye occurred near the edge of the otolith and further from the core then the last annulus, which indicated the Walleye were introduced to Swan Lake after the annulus was formed (winter 2015) and before the fish were captured (October 2015).

The following descriptive statistics compare the mean Swan Lake Walleye geochemical core values to edge values, and the Swan Lake Walleye core values to the Swan Lake Lake Trout core values. The Swan Lake Walleye ${ }^{87} \mathrm{Sr} /{ }^{86} \mathrm{Sr}$ core values $(n=2, m=0.712, s d=0.0002)$ were lower compared to the ${ }^{87} \mathrm{Sr} /{ }^{86} \mathrm{Sr}$ edge values $(n=2, m=0.727, s d=0.0003)$ (Figure $\left.2 \mathrm{~A}\right)$. The Swan Lake Walleye Sr/Ca core values $(n=2, m=1.3, s d=0.18)$ were higher compared to the $\mathrm{Sr} /$ Ca edge values $(n=2, m=0.56, s d=$ 0.11) (Figure 2B). The Swan Lake Walleye ${ }^{87} \mathrm{Sr} /{ }^{86} \mathrm{Sr}$ core values $(n=2, m=0.712, s d=0.0002$ ) were lower compared to the ${ }^{87} \mathrm{Sr} /{ }^{86} \mathrm{Sr}$ core values of the Lake Trout $(n=3, m=0.733, s d=0.0007)$ (Figure 2A). The Swan Lake Walleye Sr/Ca core values $(n=2, m=1.3, s d=0.18)$ were higher compared to the $\mathrm{Sr} / \mathrm{Ca}$ values of the Lake Trout $(n=3, m=0.574, s d=0.06)$ (Figure 2B). 
${ }^{87} \mathrm{Sr} /{ }^{86} \mathrm{Sr}$ and $\mathrm{Sr} / \mathrm{Ca}$ values showed discriminatory power based on intra-waterbody similarities

176 and inter-waterbody differences (Figure 3). The average within waterbody standard deviation in

$177{ }^{87} \mathrm{Sr} /{ }^{86} \mathrm{Sr}$ core values was 0.00013 , and the average standard deviation in Sr/Ca values equaled 0.072. In

178 contrast, we found inter-waterbody range in ${ }^{87} \mathrm{Sr} /{ }^{86} \mathrm{Sr}$ values from $0.723-0.708$ and a Sr/Ca range of 1.35-

1790.39 (Figure 3). We used ${ }^{87} \mathrm{Sr} /{ }^{86} \mathrm{Sr}$ and $\mathrm{Sr} / \mathrm{Ca}$ otolith core values from three Walleye captured in popular

180 Walleye fisheries in the state of Montana (Table 1) and the Columbia River to train the DFA and predict

181 the natal origin of the two illegally introduced Swan Lake Walleye (Figure 3). Individual geochemical

182 data for Walleye otoliths used in the DFA model can be found in the supplementary information (Table

183 S1). The DFA correctly classified $95 \%$ of individuals in the training dataset based on jackknifed leave-one-

184 out predictions, which assess the accuracy of the predictions by excluding one observation, formulating

185 a DFA using the remaining data, and using the function to classify the excluded observation. The only

186 mis-classifications occurred in Fresno and Tongue River Reservoir (Figure 3). Using the DFA to predict

187 the origin of the 2 Swan Lake Walleye both individuals classified to Lake Helena with 0.99 and 0.98

188 posterior probabilities.

\section{DISCUSSION}

Our analysis determined Swan Lake Walleye were introduced to Swan Lake based on an abrupt

192 shift in geochemical signatures from the otolith core to edge, representing a chemical inflection point

193 (Figure 2), which corresponds to a shift in water chemistry. The geochemical inflection point has been

194 used to infer life history shifts in natural populations (Miller et al. 2011; Hegg et al. 2013), as well as in

195 illegal introductions (Munro et al. 2005). The rapid geochemical change in the Walleye core to edge

196 transect was unlike the stable geochemical signature of Lake Trout from Swan Lake, which indicates the

197 Lake Trout spent their entire lives in a waterbody with homogenous geochemistry. Comparing the core 
198

199

200

201

202

203

204

to edge geochemical signatures of these two species helped confirm the Walleye were illegally introduced, and not progeny of a reproducing population in Swan Lake. Munro et al. (2005) found a $256 \%$ change in Sr/Ca signatures during otolith core to edge geochemical analysis of Lake Trout illegally introduced to Yellowstone Lake. We found a $2.2 \%$ average change in ${ }^{87} \mathrm{Sr} /{ }^{86} \mathrm{Sr}$ and $49.44 \%$ change in $\mathrm{Sr} / \mathrm{Ca}$ between core to edge geochemical signatures (Figure 2). Similar to this study, Munro et al. 2005 found Lake Trout otolith samples with stable otolith core to edge geochemical signatures, which they concluded were naturalized in Yellowstone Lake.

An alternative explanation for the rapid geochemical change in the Walleye core to edge transect is a migration within the interconnected Swan River system, in their recent life history. Although we did not collect data on Swan River geochemical signatures, such an explanation is very unlikely given the fact that 35 years of annual electrofishing in the Swan River and its tributaries, and extensive long-term gillnetting in Swan Lake, have not detected Walleye.

We formed a geochemical database of $\mathrm{Sr}$ geochemical signatures $\left({ }^{87} \mathrm{Sr} /{ }^{86} \mathrm{Sr}, \mathrm{Sr} / \mathrm{Ca}\right)$ using three Walleye otoliths from the 13 populations that had the greatest number of annual angler days in Montana. Although many studies have used ${ }^{87} \mathrm{Sr} /{ }^{86} \mathrm{Sr}$ and trace elements to predict the natal origin of fishes (Bacon et al. 2004; Walsworth et al. 2014; Walther and Nims 2015), to our knowledge this is the first study to predict the origin of illegally introduced fish over a large geographic area (state of Montana). The DFA model showed high classification accuracy (95\% accurate with jackknife resampling) because of the unique and temporally stable geochemical signatures of the otoliths from the analyzed waterbodies (Figures 3). The DFA suggests that of the waterbodies sampled, Lake Helena is the probable source of the Swan Lake Walleye illegal introduction. When classifying the natal origins of invasive fish, a study in the Upper Colorado River Basin also found distinctive and temporally stable reservoir values of ${ }^{87} \mathrm{Sr} /{ }^{86} \mathrm{Sr}$, on a decadal scale (Wolff et al. 2012). Large waterbodies likely contain 
221 temporally stable ${ }^{87} \mathrm{Sr} /{ }^{86} \mathrm{Sr}$ geochemical signatures because their large drainage areas dampen effects of

222 hydrology and climate fluctuation on water storage, thus mixing sufficiently to contain uniform water

223 chemistry (Wolff et al. 2012). Although it did not affect our discriminatory power, we found minor

224 variability in Sr/Ca geochemical signatures within otoliths because of natural physiological, biological,

225 and temporal fluctuation in fish uptake rates (Walther and Thorrold 2009).

Recognizing that the Walleye could have originated in numerous places over a large geographic

227 area, waterbodies with Walleye populations were sampled based on Walleye angler days and proximity

228 to Swan Lake. We hypothesized that these factors were important in determining probable sources of

229 the illegal introduction and were included in the geochemical reference baseline (Munro et al. 2005;

230 Wolf et al. 2012). However, given the technological advances in the aquarium equipment and boat

231 livewell tanks, it is possible to keep Walleye alive for many days after capture. Therefore, we cannot

232 eliminate the possibility that the illegally introduced Walleye could have originated in a waterbody that

233 was not sampled in this study and possesses a geochemical signature similar to Lake Helena.

234 Additionally, given the similar geochemical values of Canyon Ferry and Holter reservoirs to Lake Helena,

235 as well as their close proximity and fluvial connectivity, it is possible that the Walleye originated from

236 these waterbodies within this complex of Missouri River impoundments.

The threat of invasive non-native species to global biodiversity and ecosystem heath is a

238 complex ecological, social, and economical problem (Jenkins 2003; Simberloff et al. 2013). The rapid

239 increase in non-native freshwater fish invasions (Leprieur et al. 2009; Cucherousset and Olden 2011) is

240 particularly alarming given the mechanism has shifted from agency authorized introductions of game

241 and forage fishes in the $20^{\text {th }}$ century, to unauthorized introductions of game fish in the $21^{\text {st }}$ century

242 (Rahel 2004). Here we highlight the value in collecting suspected illegally introduced fishes' otoliths, not

243 only to investigate the natal source, but also to build a geochemical database of waterbodies that can be 
244

245

246

247

248

249

250

251

252

253

254

255

256

257

258

259

260

261

262

263

264

265

266

used to identify sources of future illegal fish introductions. Montana Fish, Wildlife \& Parks is constructing a database for all geochemical samples collected in lotic and lentic waterbodies that would allow quick response to the detection of future illegal fish introductions. Expansion and inclusion of samples from waterbodies across jurisdictional boundaries would expand this Sr isoscape database and improve the usefulness of this tool for fisheries managers addressing the problem of illegal fish introductions.

This case study provides a tool to fisheries professionals that may improve the problem of illegal fish introductions by providing law enforcement information about where the crime was initiated. Such awarness can aid investigators by determining a place to start looking for additional evidence such as a personal witness, webcams, boat registrations, or fishing license sales. Additionally, the analysis showed the Walleye were not naturalized in Swan Lake which provides managers information pertaining to the population status of the introduced species, therefore determining if or when actions such as suppression are imperative. Previous research has described the human dimensions and motivations behind the crime of illegal fish transport and introduction, concluding that education and outreach are key strategies in addressing the issue (Rahel 2004; Johnson et al. 2009). In this instance, a $\$ 30,000$ USD reward for information leading to the conviction of the person that introduced the Walleye to Swan Lake was initiated. Large fines and loss of fishing privileges through a conviction and subsequent sentencing could help deter further illegal introductions. Ultimately, confronting the problem of illegal fish introductions will require a significant resource investment that incorporates a public outreach program to protect the value of the fisheries they threaten. 
We are grateful to the Montana Fish, Wildlife and Parks biologists that collected walleye otoliths throughout the state including Leo Rosenthal, Ryan Kreiner, Heath Headley, Eric Roberts, Dave Yerk, Mike Ruggles, Cody Nagel, and Ben Bailer. The geochemical analysis was conducted at the Woods Hole Oceanographic Institution by Jerzy S. Blusztajn. Mark Deleray, Matt Boyer, and two anonymous reviewers provided helpful comments that improved this manuscript. SLB was supported by Bonneville Power Administration grant \#199101903 to Montana Fish, Wildlife and Parks while preparing this manuscript.

\section{REFERENCES}

Azevedo-Santos, V. A., Vitule R. S., Garcia-Berthou, E., Pelicice, F. M., and Simberloff, D. 2016. Misguided

Bacon, C. R., Weber, P. K., Larsen, K. A., Reisenbichler, R., Fitzpatrick, J. A., and Wooden, J. L. 2004. Migration and rearing histories of Chinook salmon (Oncorhynchus tshawytscha) determined by ion microprobe Sr isotope and Sr/ca transects of otoliths. Can. J. Fish. Aquat. Sci. 61: 2425-2439. doi: 10.1139/f04-167.

Barnett-Johnson, R. Pearson, T. E., Ramos, F. C., Grimes, C. B., and MacFarlan, R. B. 2008. Tracking natal origins of salmon using isotopes, otoliths, and landscape geology. Limnol. Oceanogr. 53(4): 1633-1642. doi: 10.4319/lo.2008.53.4.1633.

Becker, R. A., Wilks, A. R., Brownrigg, R., Minka, T. P., and Deckmyn, A. 2017. maps: Draw Geographical Maps. R Package Version, 3.2.0. Available: https://CRAN.R-project.org/package=maps.

Benson, A. J. 1999. Documenting over a century of aquatic introduction in the United States. In Nonindigenous freshwater organisms: vectors, biology, and impacts. Edited by R. Claudio and J. H. Leach. CRC Press LLC, Boca Raton, Florida. pp. 1-31.

Bourret, S. L., Kennedy, B. P., Caudill, C. C., and Chittaro, P. M. 2014. Using otolith chemical and structural analysis to investigate reservoir habitat use by juvenile Chinook salmon Oncoryhnchus tshawytsha. J. Fish Biol. 5(85): 1507-1525. doi: 10.1111/jfb.12505. 
Brennan, S. R., Zimmerman, C. E., Fernandez, D. P., Cerling, T. E., McPhee, M. V., and Wooller, M. J. 2015. Strontium isotopes delineate fine-scale natal origins and migration histories of Pacific salmon. Sci. Adv. 15: 1-6. doi: 10.1126/sciadv.1400124.

Campana, S. E., and Thorrold, S. R. 2001. Otoliths, increments and elements: Key to a comprehensive understanding of fish populations? Can. J. Fish. Aquat. Sci. 58: 30-38. doi: 10.1139/f00-177.

Cucherousset, J., and Olden, J. D. 2011. Ecological impacts of non-native freshwater fishes. Fisheries, 36(5): 215-230. doi.:10.1080/03632415.2011.574578.

Garcia-Berthou, E. 2007. The characteristics of invasive fishes: what has been learned so far? J. Fish Biol. 71: 33-55. doi:10.1111/j.1095-8649.2007.01668.

Hegg, J. C., Kennedy, B. P., Chittaro, P., and Zabel, R. W. 2013. Spatial structuring of an evolving lifehistory strategy under altered environmental conditions. Ocecologia, 172(4): 3-17. doi:10.1007/s00442-012-2564-9.

Hilton-Taylor, C., Vie, J., and Stuart, S. N. 2009. Wildlife in a changing world- an analysis of the 2008 IUCN red list of threatened species. Gland, Switzerland: IUCN.

Jenkins, M. 2003. Prospects for Biodiversity. Science, 302(1175): doi.org/10.1126/science.1088666.

Jeschke, J. M., and Strayer, D. L. 2006. Determinants of vertebrate invasion success in Europe and North America. Glob. Change Biol. 12: 1608-1619. doi: 10.1111/j.1365-2486.2006.01213.

Johnson, B. M., Arlinghaus, R., and Martinez, P. J. 2009. Are we doing all we can to stem the tide of illegal fish stocking? Fisheries, 34(8): 389-394. doi:10.1577/1548-8446-34.8.389.

Kennedy, B. P., Folt, C. L., Blum, J. D., and Chamberlain, C. P. 1997. Natural isotope markers in salmon. Nature, 387(6635): 766-767. doi: 10.1038/42835.

Kennedy, B. P., Folt, C. L., Blum, J. D., and Nislow, K. H. 2000. Using natural strontium isotopic signatures as fish markers: methodology and application. Can. J. Fish Aquat. Sci. 57: 2280-2292. doi: 10.1139/f00-206.

Leprieur, F., Brosse, S., Garcia-Berthou, E., Oberdorff, T., and Olden, J. D., and Townsend, C. R. 2009. Scientific uncertainty and the assessment of risks posed by non-native freshwater fishes. Fish Fish. 10: 88-97. doi:10.1111/j.1467-2979.2008.00314.

Mack, R. N., Simberloff, D., Lonsdale, W. M., Evans, H., Clout, M., and Bazzaz, F. A. 2000. Biotic invasions: causes, epidemiology, global consequences, and control. Ecol. Appl. 10(3): 689-710. doi:10.1890/1051-0761(2000)010[0689:BICEGC]2.0.CO;2.

Marr, S. M., Marchetti, M. P., Olden, J. D., Garcia-Berthou, E., Morgan, D. L., Arismendi, I., Day, J., Griffiths, C. L., and Skelton, P. H. 2010. Freshwater fish introductions in mediterranean-climate regions: Are there commonalities in the conservation problem? Diversity and Distributions. 16: 606-619. doi:10.1111/j.1472-4642.2010.00669. 
Mckinney, M. L., and Lockwood, J. L. 1999. Biotic homogenization: a few winners replacing many losers in the next mass extinction. Trends Ecol. and Evolut. 14(11): 450-453.

Miller, J. A., Butler, V. L., Simenstad, C. A., Backus, D. H., and Kent, A. 2011. Life history variation in upper Columbia River Chinook salmon (Oncorhynchus tshawytscha): a comparison using modern and 500-year-old archaeological otoliths. Can. J. Fish. Aquat. Sci. 68: 603-617.

Muhlfeld, C. C., Marotz, B., Thorrold, S. R., and Fitzgerald, J. L. 2005. Geochemical signatures in scales record stream origin in westslope cutthroat trout. Trans. Am. Fish. Soc. 134(4): 945-959. Doi:10.1577/T04-029.1.

Muhlfeld, C. C., Thorrold, S. R., McMahon, T. E., and Marotz, B. 2012. Estimating westslope cutthroat trout (Oncorhynchus clarkia lewisi) movements in a river network using strontium isoscapes. Can. J. Fish. Aquat. Sci. 69: 1-10. doi: 10.1139/F2012-033.

Munro, A. R., Mcmahon, T. E., and Ruzycki, J. R. 2005. Natural chemical markers identify source and date of introduction of an exotic species: lake trout (Salvelinus namaycush) in Yellowstone Lake. Can. J. Fish Aquat. Sci. 62: 79-87. doi:10.1139/F04-174.

Nielsen, L. A. 1999. History of inland fisheries management in North America. in Fisheries management in North America, $2^{\text {nd }}$ edition. Edited by C. C. Kohler and W. A. Hubert. Inland American Fisheries Society, Bethesda, Maryland. pp. 3-30.

Rahel, F. J. 2000. Homogenization of fish faunas across the United States. Science, 288(5467): 854-856. doi:10.1126/science.288.5467.854.

Rahel, F. J. 2004. Unauthorized fish introductions: fisheries management of the people, for the people, or by the people? American Fisheries Society Symposium. 44: 431-443.

Rahel, F. J., and Olden, J. D. 2008. Assessing the Effects of Climate Change on Aquatic Invasive Species. Conserv. Biol. 22(3): 521-533. doi:10.1111/j.1523-1739.2008.00950.

Russell, J. C., and Blackburn, T. M. 2017. The rise of invasive species denialism. Trends Ecol. Evol. 32(1): 3-6. doi: 10.1016/j.tree.2016.10.012.

Simberloff, D., Martin, J., Genovesi, P., Maris, V., Wardle, D. A., et al. 2013. Impacts of biological invasions: what's what and the way forward. Trends Ecol. Evol. 28: 58-66. doi: 10.1016/j.tree.2012.07.013.

Vander Zanden, M. J., and Olden, J. D. 2008. A management framework for preventing the secondary spread of aquatic invasive species. Can. J. Fish Aquat. Sci. 65: 1512-1522. doi.org/10.1139/F08099.

Weber, M., Lugli, K. P., Jochum, A. C., and Scholz, D. 2017. Calcium carbonate and phosphate reference materials for monitoring bulk and microanalytical determination of Sr isotopes. Geostand. Geoanal. Res. 41. Doi:10.1111/ggr.12191. 
Wells, B. K., Rieman, B. E., Clayton, J. L., Horan, D. L., and Jones C. M. 2003. Relationship between water, otolith, and scale chemistries of Westslope Cutthroat Trout from the Coeur d'Alene River, Idaho: the potential application of hard-part chemistry to describe movements in freshwater. Trans. Am. Fish. Soc. 132(3): 409-424. doi: 10.1577/1548-8659(2003)132<0409:RBWOAS>2.0.CO;2.

Walsworth, T. E., Schindler, D. E., Griffiths, J. R., and Zimmerman, C. E. 2014. Diverse juvenile life-history behaviours contribute to the spawning stock of an anadromous fish population. Ecol. Freshw. Fish, 24(2): 204-213. doi: 10.1111/eff.12135.

Walther, B. D., and Thorrold, S. R. 2009. Inter-annual variability in isotope and elemental ratios recorded in otoliths of an anadromous fish. J. Geochem. Explor. 102(3): 181-186. doi: 10.1016/j.gexplo.2008.10.001.

Walther, B. D., and Nims, M. K. 2015. Spatiotemporal variation of trace elements and stable isotopes in subtropical estuaries: I. freshwater endmember and mixing curves. Estuaries and Coasts. 38:754-768. doi: 10.1007/s12237-014-9881-7.

Wolff, B. A., Johnson, B. M., Breton, A. R., Martinez, P. J., and Winkelman, D. L. 2012. Origins of invasive piscivores determined from the strontium isotope ratio $\left({ }^{87} \mathrm{Sr} /{ }^{86} \mathrm{Sr}\right)$ of otoliths. Can. J. Fish Aquat. Sci. 69: 724-739. doi: 10.1139/F2012-009.

\section{Figure Captions}

Figure 1. Map of Montana showing waterbodies where Walleye were sampled to build the geochemical database (in blue). Swan Lake is highlighted in red (Becker et al. 2017).

Figure 2. A) Otolith ${ }^{87} \mathrm{Sr} /{ }^{86} \mathrm{Sr}$ core to edge profiles of fish captured in Swan Lake including the two Walleye and three Lake Trout. B) Otolith Sr/Ca core to edge profiles of fish captured in Swan Lake including the two Walleye and three Lake Trout.

Figure 3. Bivariate scatterplot showing the distribution in Strontium isoscapes from otoliths of fish sampled from throughout Montana for the walleye geochemical database, including the two illegally introduced Swan Lake Walleye. Each dot represents an individual walleye otolith from its color-coded sample location. 
Table 1. The top 13 most angled Walleye fisheries in Montana based on mail in angler creel surveys. Also included is the distance to Swan lake of each fishery via road kilometers.

\begin{tabular}{lll} 
Water Body & Angler Days & Distance to Swan lake (road km) \\
\hline Canyon Ferry & 3983 & 299 \\
Fort Peck Res. & 3962 & 742 \\
Holter & 1510 & 253 \\
Tiber & 1078 & 360 \\
Fresno & 906 & 444 \\
Nelson Res. & 881 & 631 \\
Cooney Res. & 776 & 616 \\
Frances & 657 & 432 \\
Hauser & 589 & 298 \\
Tongue River Res. & 415 & 929 \\
Bighorn Res. & 340 & 851 \\
Lake Helena & 228 & 309 \\
Noxon Rapids Res. & 103 & 261 \\
\hline
\end{tabular}




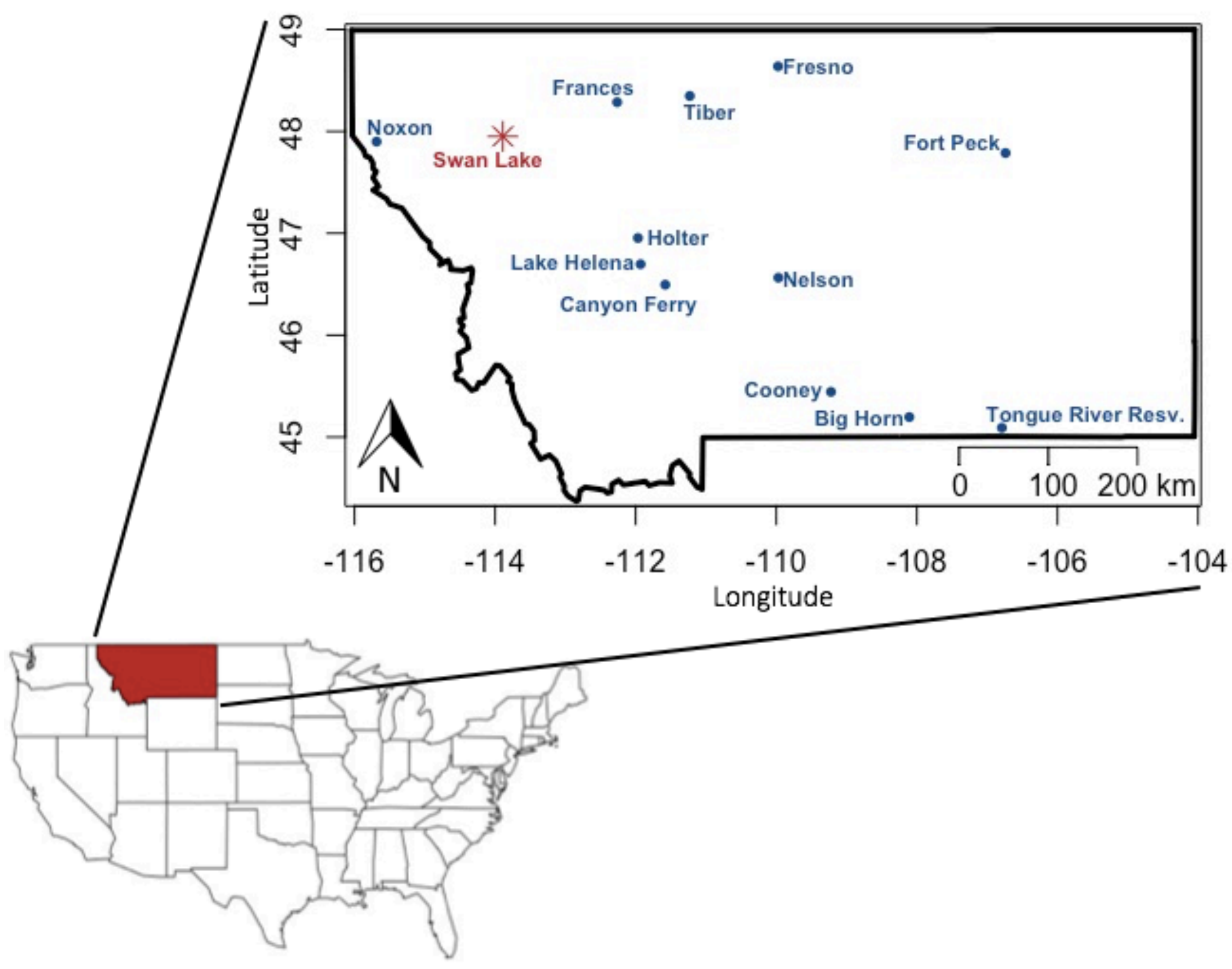




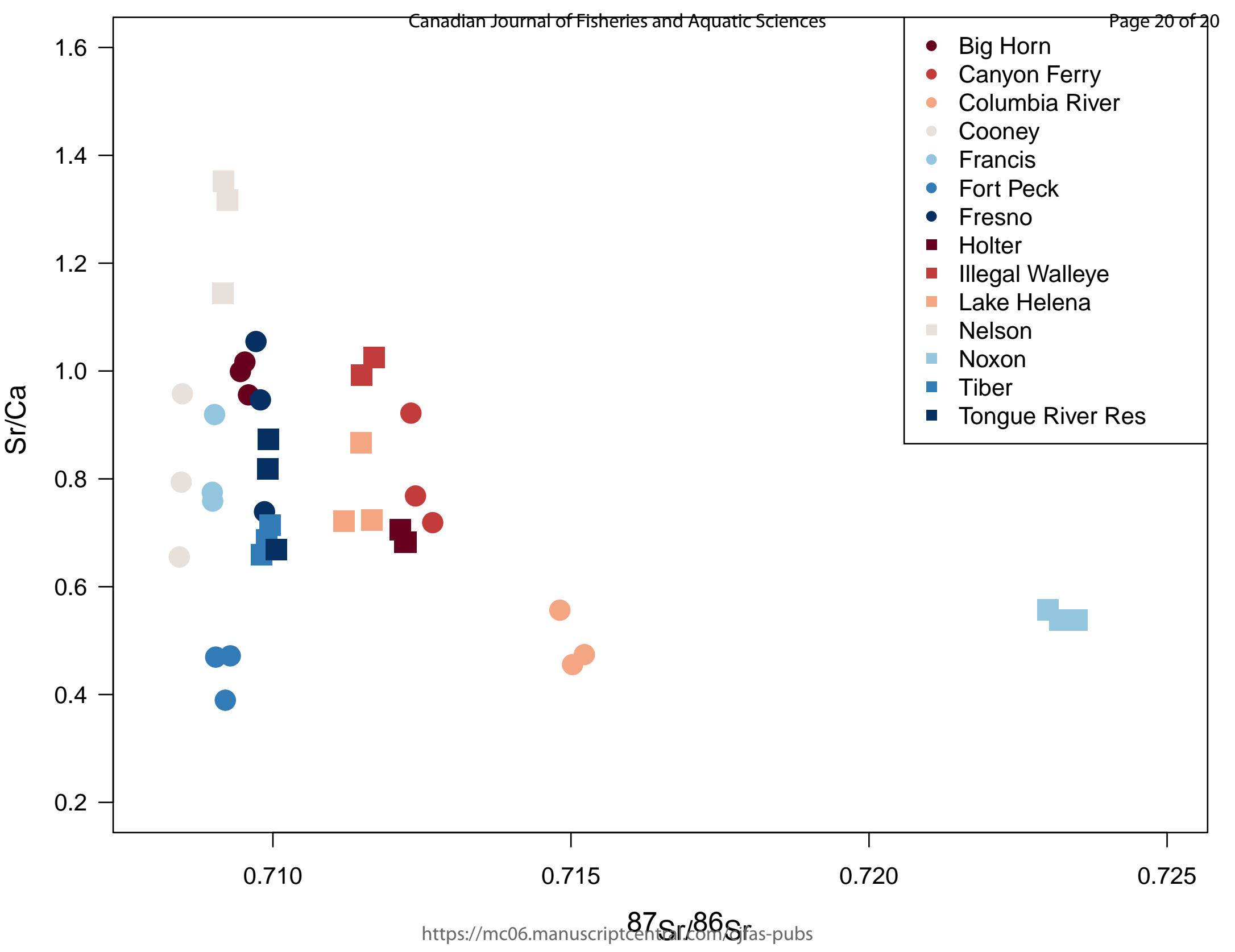

